\title{
Learning PLM System with a Serious Game
}

\author{
Philippe Pernelle ${ }^{1}$, Stephane Talbot ${ }^{2}$, Thibault Carron ${ }^{3}$, \\ and Jean-Charles Marty ${ }^{4}$ \\ 1 University of Lyon 1, Laboratory DISP \\ F-69621 Villeurbanne Cedex, France \\ philippe.pernelle@univ-lyon1.fr \\ 2 University of Savoie \\ F-73000 Chambery, France \\ stephane.talbot@univ-savoie.fr \\ 3 Laboratory LIP6 \\ F-75013 Paris , France \\ thibault.carron@lip6.fr \\ ${ }^{4}$ Laboratory LIRIS \\ F-69621 Villeurbanne Cedex, France \\ jean-charles.marty@liris.cnrs.fr
}

\begin{abstract}
Despite improvements in educational tools, teaching some elements in the field of production engineering is difficult. In this context, teaching PLM systems remains difficult from a motivation point of view. The purpose of this paper is to propose a highly innovative approach around serious gaming. In the PEGASE project, we have realized an environment for coupling a gaming platform and a content platform in order to enact learning scenarios. This article presents this integration environment which is based on the characterization of business activities within the PLM. Then, we describe the design of scenarios in this platform particularly dedicated to learning PLM systems. We then present the validation of our approach based on different experiments performed with students and with industrial partners.
\end{abstract}

Keywords: Game Base Learning, Serious Game, PLM.

\section{Introduction}

Teaching production engineering is difficult, and particularly for PLM systems. There are many reasons for this. The first reason is that students learn CAD systems without management constraints. When they find out PLM systems, constraints are more visible than the benefits. The second and probably more important, reason is that it is very expensive (in terms of financial cost and human resources) for an educational establishment : Installation, configuration, collaborative projects management...

In this paper, we propose a new approach for learning PLM system: learning a unit with Serious Game. This unit has been produced as part of a research project (PEGASE) that was initially intended to improve the change management. Noting the fact that resistance to change were the same for enterprises 
and students, we developed a learning scenario using the playful aspects of the video games. In the first part, we present the concept of this Serious Game, then we present the experiment results that was achieved with students.

\section{New Learning for PLM Systems}

\subsection{About the Games Learning Bases}

Since a few years, Learning Management Systems (LMS) offer functionalities that are recognized as being valuable from different points of view [1]. For instance, students can learn at their own speed. These environments also allow the teacher to evaluate specific activities in a uniform way [2]. LMS allow to structure and to develop distance training. However they have not enough impact on the motivation and the attractiveness. Some students tend to consider LMS as unexciting [3. So, Game-Based Learning Management System is based on that the way of acquiring knowledge during a learning session is similar to following an adventure in a Role-Playing Game (RPG) 4]. The combination of the two styles is called MMORPG (Massively Multiplayer Online RPG) and offers a good potential for learning reformulated as MMOLE (Massively Multiplayer Online Learning Environment) [5]. Nevertheless, although the students appreciate this approach and that Games-based Learning can significantly enhance learning, there is an obvious need for realistic information about students: skills, actions or behaviors especially for the teacher [6].

The difficulties that teachers face in teaching PLM System to students incited us to find additional motivation thanks to Game-Based Learning (GBL). Although the project below was not initially intended for this, we have conducted experiments to test this.

\subsection{PEGASE : A Serious Game for PLM}

PEGASE project [7 8] is a Serious Game based on Learning Adventure ("LA") 9]. $L A$ is a Game-Based Learning Management System representing a 3D environment where the learning session takes place (see Fig. 1). The environment is generic in the sense that it is not dedicated to a particular teaching domain. With the help from a pedagogical engineer, the teacher adapts the environment before the session by setting pre-requisites between sub-activities and by providing different resources (documents, videos, quizzes) linked to the course. Experiments have already been set up for learning Operating Systems as well as Project Management or Object Oriented Concepts in Computer Science. $L A$ is thus a platform allowing one to describe, generate and enact different learning environments. The following items define the main characteristics of $L A$ :

- A 2D or 3D multiplayer world, split into activity areas;

- Artefacts populating this world: objects, individual or collaborative tools, non-player characters (NPC), players represented by their avatars; 
- Possibility to characterize the players / learners through a learner/user model and also through group models;

- Enacting facilities

- Avatar personalisation

- Tracing facilities of players' actions

- Tools for designing scenarios

- Scenario or quest editor, evaluation tools

- Possibility to modify dynamically the environment.

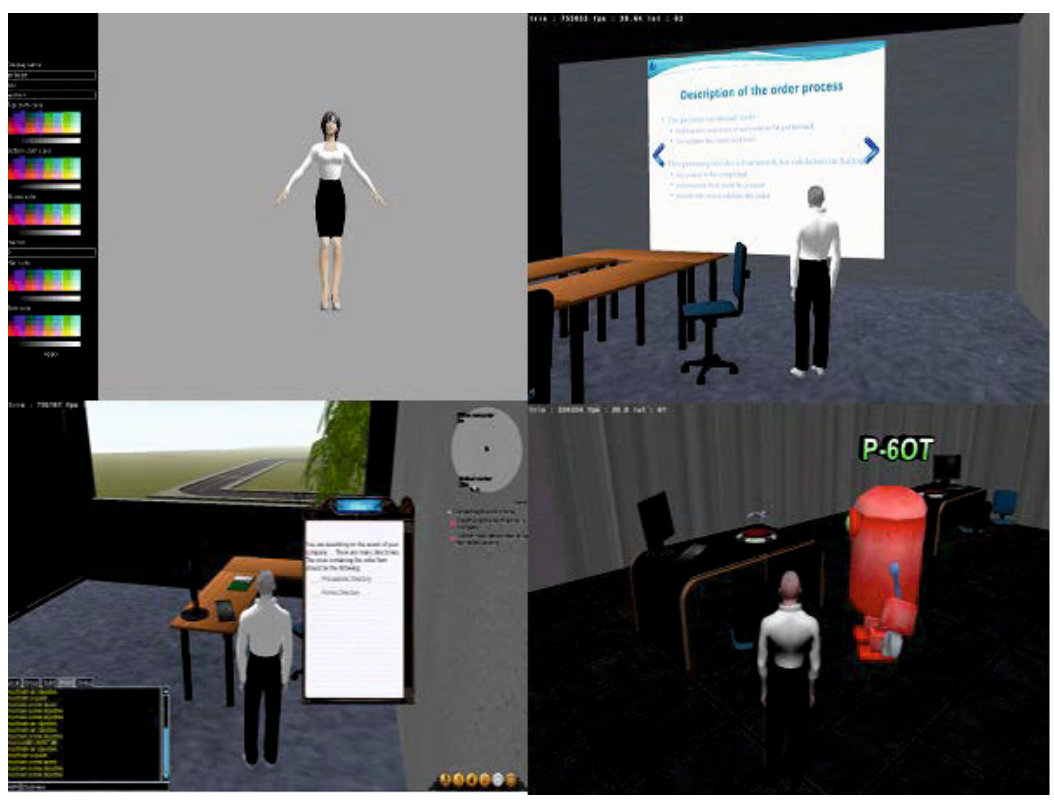

Fig. 1. Screenshots of the Learning Adventure $(L A)$ environnement

In the PEGASE project, the gaming environment is associated to a content platform (Audros). This content platform is a PLM system very used in SME/SMI. Moreover, a Trace-Based System (TBS) captures the behavioral traces and activity traces. These traces are essential to monitor the progress of the users in the scenario. Thus, after several steps (collection, selection, transformation, aggregation of different traces), we are able to provide specific indicators [10] giving meaningful information to the teacher (see Fig. 2). Moreover, some of these indicators may also be used to update the user model of each student and to present accurate information for the teacher. The interoperability issues have been resolved by relying on a service-oriented architecture [11] (see Fig. 2). 


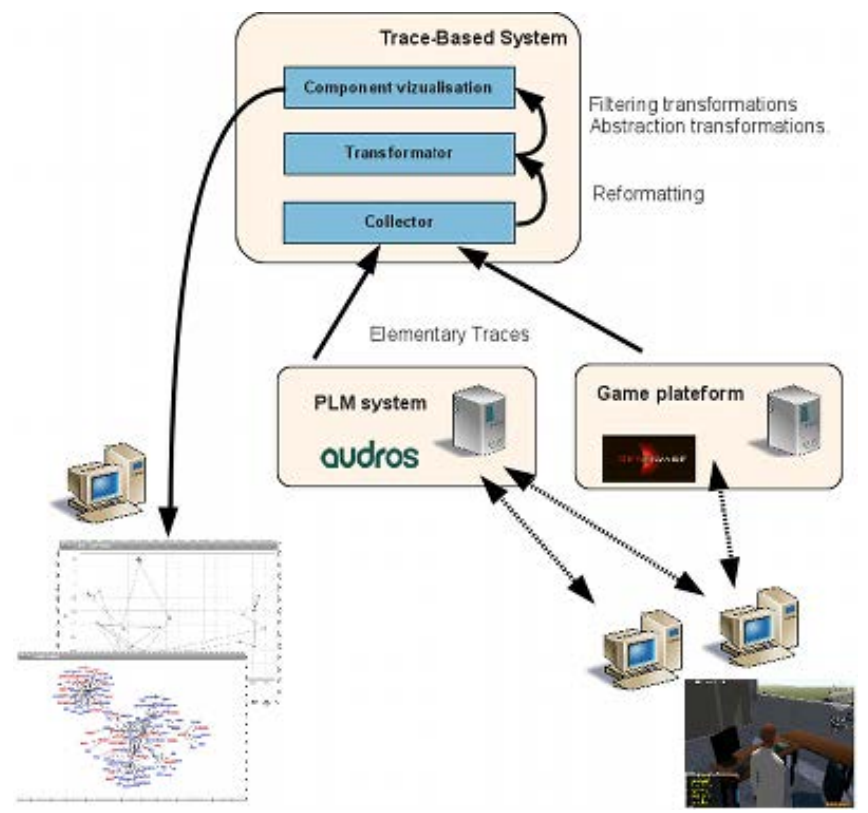

Fig. 2. PEGASE architecture

\section{An Example of a Pedagogical Scenario for PLM}

In order to design a pedagogical scenario for PLM, we looked for an industrial process that was sufficiently generic to be used by any student. This process referred to a case study from the plastic industry. The transformation of an industrial process into a pedagogical scenario was achieved thanks to research work concerning gamification [12].

This architecture is generic in sense that it can design any pedagogical scenario. We chose to conceive a first scenario for discovering the main functions of PLM. In the design stage, this classification enables the trainer to build his scenario from a descriptive guide. Initially, the proposed scenario was structured around a simple industrial process (purchase order) described in Figure 3 . Without a PLM system, this process is achieved through traditional activities where the risk of error, as well as the tedious tasks involved, should be considered.

In a first part, this process is carried out in the PEGASE Serious Game without any PLM system. The following items and figures describe the corresponding actions:

- Discussion with colleagues and watching a training presentation (see Figure 4);

- Collecting documents in order to complete and visualize the tasks in the process;

- Visualization of the order form, retrieval of information from the archives; 

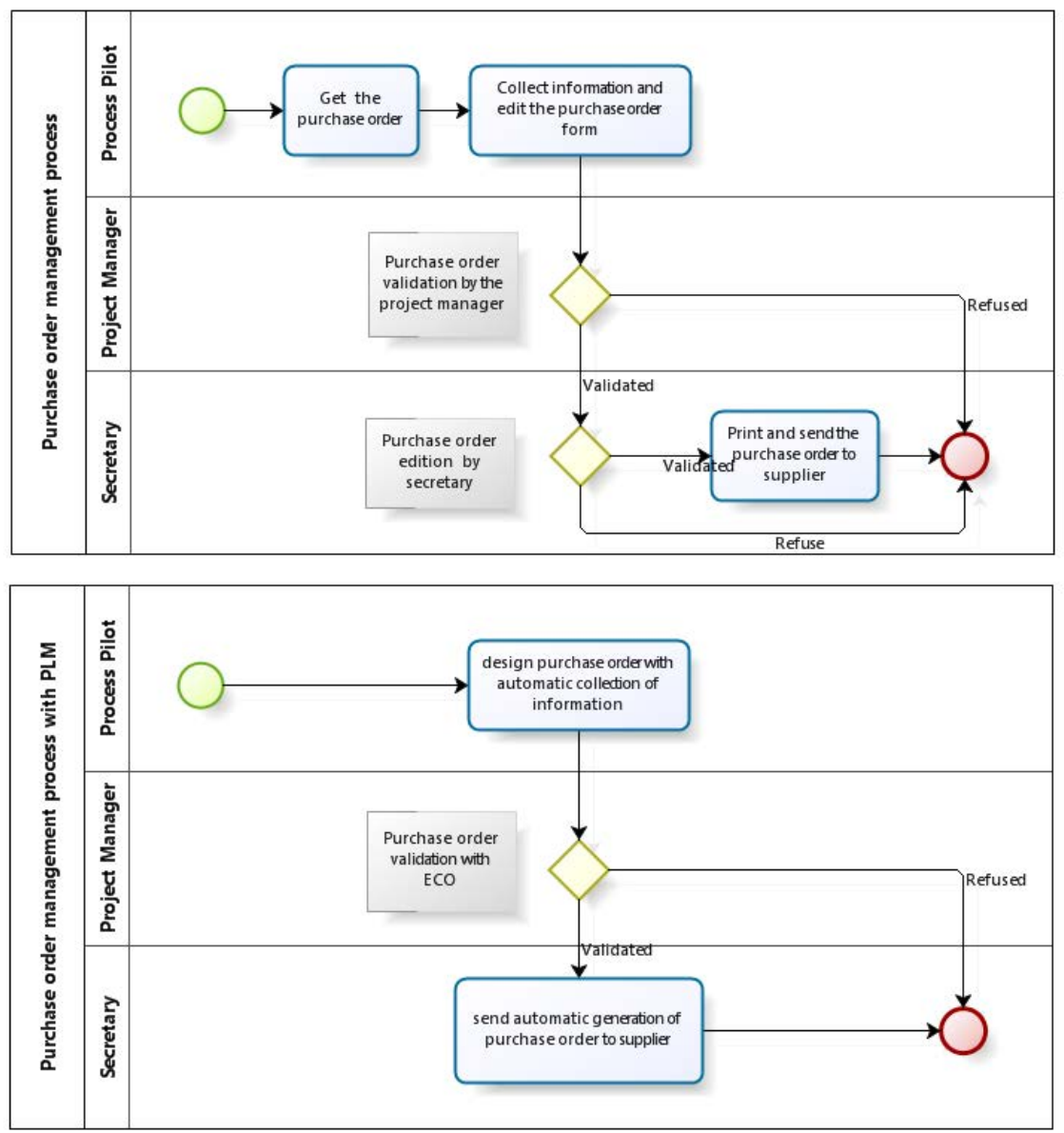

Fig. 3. Purchase order management process with and without PLM

- Summary of time-consuming steps (see Figure 55);

- Explanation for creating a purchase order with Audros platform(see Figure 6);

Once the process is carried out without a PLM system, a collective and individual balance of mistakes made by the player is presented. A mini training session on possible solutions to resolve their mistakes with the Audros PLM system is then proposed. The process is therefore performed with a connection to the Audros platform.

\section{Experiment of this Scenario}

An experiment was carried out from September 2011 to December 2011 in the Technical Institute (Lyon - France) with 224 students. During the experiment, each group of twelve students with their teacher was present in the classroom equipped 


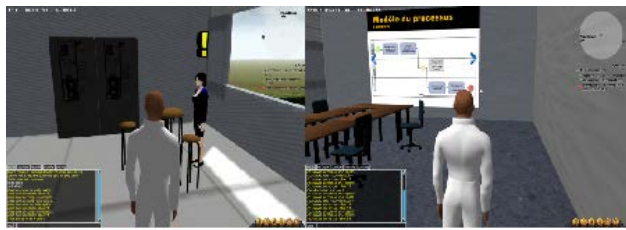

Fig. 4. PEGASE screenshot: a player interacting with the game environment

\begin{tabular}{|c|c|c|}
\hline है & $\begin{array}{l}\text { Coffeemachine:Meeting with the } \\
\text { skilled worker }\end{array}$ & $\begin{array}{l}\text { You understood the problem happening in the } \\
\text { company }\end{array}$ \\
\hline (8) & $\begin{array}{l}\text { Meeting room: Consulting the } \\
\text { procedure }\end{array}$ & $\begin{array}{l}\text { You satw the video describing the process of tooling } \\
\text { ondering treatement }\end{array}$ \\
\hline & Office & You have retrieved the order form \\
\hline का & $\begin{array}{l}\text { Factory floor: Meeting with } \\
\text { the skilled worker }\end{array}$ & $\begin{array}{l}\text { You have collected the information to prepare the } \\
\text { order form }\end{array}$ \\
\hline & Room of archives & $\begin{array}{l}\text { You retrieved the informution to prepare the } \\
\text { order form }\end{array}$ \\
\hline & Project manager & You searched for the project maniger \\
\hline 8 & Secretary & Secretary find errors on the order form \\
\hline
\end{tabular}

Fig. 5. PEGASE screenshot: reminder for the player's tedious tasks

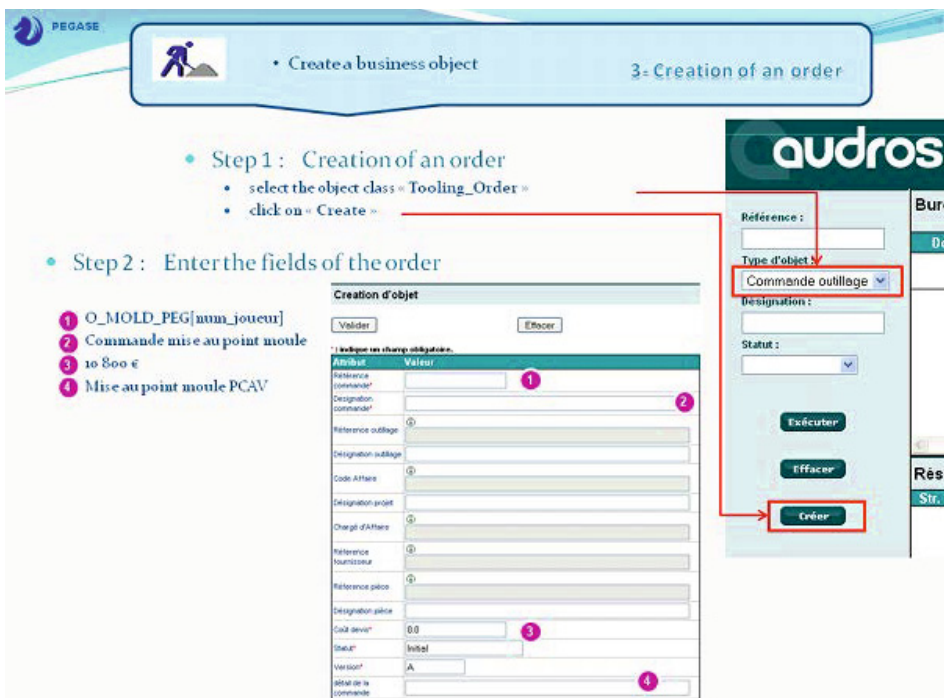

Fig. 6. PEGASE screenshot: a player interacting with Audros system 
with 12 computers. Each student accessed the virtual environment through his/her workstation, and had a personal (adapted) view on the world. They were explicitly allowed to communicate through the chat tool provided with the system and were warned that they would be observed regarding the use of the system.

As explained before, the course was dedicated to the understanding of the PLM problematic. The learning content dealt with «PLM elementary concepts»: the session was split into two parts: experimenting without (long and tedious) and with a PLM system. The solution (final document) had to be approved by a PLM system expert who was online via the PLM business tool (Audros) and was receiving each document produced. The aim of the session was to assess the knowledge and know-how of the students about the objectives of a PLM system. A story guided the knowledge quest thanks to metaphors. Indeed, the challenge is encouraged through NPC who propose a coherent contest. Immersion is reinforced when the users' actions have a direct impact on the objects of the world. Finally, the teacher was also present in the game via an avatar: it was possible to chat with him, to ask for help for example.

Looking at the experiment results with regard to previous years when this module was done without SG, we observed two improvements. The first is a very slight increase in overall average. However, there is a significant reduction of the standard deviation. This is confirmed by a survey showing that there were fewer unmotivated students than usual.

\section{Conclusion}

In this article, we have illustrated an example of new learning technologies for PLM system. Using a serious game has shown very positive effects. This allows to more easily accept the PLM system constraints. Furthermore, students' motivational level for deepening such systems, is greatly increased.

Naturally, some drawbacks persist: we must recognize that it is very difficult for the teacher to be both present in the game, help the students and regulate the session even with these specific tools. We currently think that we can develop some specific indicators only dedicated to some classical fields of a domain. An interesting perspective could be to develop and propose directly within the indicators some basic regulation actions such as « play specific PLM video», « propose new activity » or « enable/disable such facility/ies for this student» in order to improve and adapt the learning progression.

The $L A$ environment is collaborative, multiplayer and fully observable thanks to traces left by the users during the game. These traces allow us to elaborate collaborative indicators. Moreover, thanks to the feedback collected from these experiments (questionnaires and debriefing sessions directly after the game), we are able to imagine new factual indicators of collaboration exploiting traces left by the users. Future experiments will be done around collaborative activities in the PLM systems. In this brand new scenario (context : futuristic enterprise, multi-role player, handling quality non-conformance process), we want to test some advanced functionalities (ECR, ECO, co-design, ...) around the conception of some complex products. 
Acknowledgement. We would like to thank the French Ministry for the Economy, Industry and Employment (DGCIS) for the support in the PEGASE project. We would like also to thank G. Dalla Costa, A. Bissay, J. Depoil, L. Kepka, S. El Kadiri, L. Michea and M. Zrouki for their great help in developing this platform.

\section{References}

[1] Dillenbourg, P., Baker, M., Blaye, A., OMalley, C.: The evolution of research on collaborative learning. In: Learning in Humans and Machine: Towards an Interdisciplinary Learning Science, pp. 189-211 (1996)

[2] Hijon, R., Carlos, R.: E-learning platforms analysis and development of students tracking functionality. In: 18th World Conference on Educational Multimedia, Hypermedia and Telecomunications, pp. 2823-2828 (2006)

[3] Prensky, M.: Digital Game-Based Learning. MacGraw Hill (2000)

[4] Squire, K.: Videogames in education. International Journal of Intelligent Games and Simulations 2, 49-62 (2003)

[5] Yu, T.W.: Learning in the virtual world: the pedagogical potentials of massively multiplayer online role playing games. International Education Studies 2(1) (2009)

[6] Galarneau, L., Zibit, M.: Online Game for 21st Century Skills. In: Games and Simulations in Online Learning: Research and Development Frameworks, pp. 59-88. Information Science Publishing, Hersey (2007)

[7] Bissay, A., Zrouki, M., Cheballah, K., Pernelle, P.: Pegase: a platform tool to help change management support during the implementation of a plm system in an industrial company. In: 8th International Conference on Product Lifecycle Management, Eindhoven (2011)

[8] Pernelle, P., Marty, J., Carron, T.: Serious gaming: A new way to introduce product lifecycle management. In: L.U. (ed.) IEEE Workshop on Learning Technology for Education in Cloud 7th International Conference on Knowledge Management in Organizations. Services and Cloud Computing. Services and Cloud Computing, pp. 89-100. Springer (July 2012)

[9] Carron, T., Marty, J.C., Heraud, J.M.: Teaching with game based learning management systems: Exploring and observing a pedagogical dungeon. Simulation and Gaming 39(3), 353-378 (2008)

[10] Gendron, E., Pourroy, F., Carron, T., Marty, J.: Towards a structured approach to the definition of indicators for collaborative activities in engineering design. Journal of Engineering Design 7(3), 195-216 (2012)

[11] Zrouki, M., El Kadiri, S., Pernelle, P., Benmoussa, R.: Caracterisation de services metiers plm: Un exemple d integration dans le cadre du projet pegase. In: $9 \mathrm{e}$ Congres International de Genie Industriel (2011)

[12] Mayer, I.S.: he gaming of policy and the politics of gaming: A review. Simulation and Gaming 40, 825-862 (2009) 